\title{
Ejaculate allocation in Brachyura: What do males of Metacarcinus edwardsii respond to?
}

\author{
Luis Miguel Pardo ${ }^{1,2, *}$, Marcela Paz Riveros ${ }^{1}$, Oscar R. Chaparro', \\ Katrin Pretterebner ${ }^{1,2}$ \\ ${ }^{1}$ Instituto de Ciencias Marinas y Limnológicas, Facultad de Ciencias, Universidad Austral de Chile, Valdivia, Chile \\ ${ }^{2}$ Centro de Investigación de Dinámica de Ecosistemas Marinos de Altas Latitudes (IDEAL), Valdivia, Chile
}

\begin{abstract}
In polygynous species, the sperm economy hypothesis predicts that males can adjust the amount of their ejaculate during copulation in response to (1) individual traits of females according to potential female fecundity, (2) future mating opportunities, and (3) risk of sperm competition. We tested this hypothesis in the crab Metacarcinus edwardsii by performing laboratory mating experiments to compare the response of males (sperm number and ejaculate weight delivered) in 3 sex-ratio scenarios: (1) equal, 1 female:1 male; (2) male-biased, 1 female: 2 males; and (3) female-biased, 2 females:1 male. First, we determined if any variable, or an interaction between variables, could explain the variation in sperm or ejaculate amount delivered under an equal sex ratio. Second, we contrasted the ejaculate allocation among different sex-ratio scenarios. Under an equal sex ratio, males of $M$. edwardsii did not adjust their ejaculate allocation in response to any female trait. Male size was positively related to ejaculate delivery, indicating that the pair of vasa deferentia has ejaculate reserves that scale exponentially with male size. However, larger males delivered disproportionally more seminal fluid than sperm. Under a female-biased sex ratio, males did not show plasticity in their ejaculate allocation, but they increased their ejaculate investment ( $23 \%$ ) per female under a male-biased sex ratio (i.e. risk of sperm competition). $M$. edwardsii presented a low level of ejaculate allocation, responding only when competitive males were perceived. In species with trans-molt sperm retention and long ejaculate storage, the risk of sperm competition is present all the time; therefore, males do not economize ejaculate even if more receptive females are available.
\end{abstract}

KEY WORDS: Reproduction · Invertebrate $\cdot$ Sperm competition $\cdot$ Crabs

\section{INTRODUCTION}

Sexual selection is pervasive in dioecious organisms, but can be especially intense in polygynous species in which some males mate with several females and others with none. Therefore, males develop traits (i.e. size, agonistic behavior) that improve their reproductive success and help them obtain more mates (Andersson 1994).

As male reproductive material can be expensive (Dewsbury 1982), one of the strategies to maximize reproductive success in males is sperm allocation;

${ }^{*}$ Corresponding author: luispardo@uach.cl males adjust the number of sperm invested in the ejaculate. Recently, several authors have stressed that in some cases, the limited resource can be seminal fluid, especially the energetically expensive seminal proteins and lipids, rather than sperm (reviewed by Perry et al. 2013). Therefore, a correct evaluation of the reproductive investment by males needs to take at least the amount of accessory fluids in the ejaculate into account. Thus, the suitable term is ejaculate (sperm plus seminal fluids) allocation.

Variation in the amount of ejaculate transferred to females can be influenced by several traits related to

(C) The authors 2018. Open Access under Creative Commons by Attribution Licence. Use, distribution and reproduction are unrestricted. Authors and original publication must be credited. 
potential female fecundity (Reinhold et al. 2002), male size, female ejaculate storage capacity, receptivity duration of females and risk of sperm competition (Pitnick \& Markow 1994, MacDiarmid \& Butler 1999, Reinhold et al. 2002, Wedell et al. 2002, Sato et al. 2006, Wigby et al. 2009, Parker \& Pizzari 2010, Perry et al. 2013). In turn, the proportion between sperm and seminal fluid in the ejaculate can also vary depending on the levels of polyandry and sperm competition (Perry et al. 2013).

Most studies on this subject have focused on insects, with a few examples in brachyuran crabs. Brachyura have similarities in the reproductive system with insects, such as a specialized ejaculate storage organ in females. In crab species, variation in ejaculate allocation has been principally associated with male size and operational sex ratio (Jivoff 1997, 2003, Rondeau \& Sainte-Marie 2001). The ejaculate allocation strategy can also differ between populations, as has been demonstrated in the semi-terrestrial crab Neohelice granulata (Sal Moyano et al. 2015).

The proportion between sperm and seminal fluids in ejaculate can vary among crab species. For example, in the blue crab Callinectes sapidus, the amount of seminal fluid and sperm both increase with male size, but seminal fluid increases exponentially (Kendall et al. 2001). On the other hand, in the snow crab Chionoecetes opilio, the sperm number delivered by males is directly proportional to ejaculate weight (i.e. receptacle load) when they mate with primiparous females (Sainte-Marie \& Lovrich 1994, Rondeau \& Sainte-Marie 2001). Given that seminal fluid is expensive to produce (Dewsbury 1982) and has multiple functions in the reproductive process (i.e. sperm protection and nutrition, ejaculate stratification), variation in the proportions of sperm and seminal fluid delivered to females is expected depending on the male condition (i.e. size) and the sperm competition scenario. In species in which females can mate with multiple males in the same mating season, the risk of sperm competition increases and males should adjust the ejaculate investment per female (Wedell et al. 2002). Thus, under different sex-ratio scenarios, plasticity in the ejaculate load or sperm number transferred by males to females can be expected.

We tested this hypothesis using the marmola crab Metacarcinus edwardsii (Bell, 1835) as a study model. This crab species is abundant and one of the largest crabs along the Pacific coast from Guayaquil in the south of Ecuador to Islotes Haskenyeska in the Beagle Channel (Vinuesa et al. 1999). In the southern region of Chile, $M$. edwardsii is under intensive artisanal exploitation (Fischer \& Thatje 2016). M. edwardsii is univoltine, and the mating season occurs principally during late austral spring (Pardo et al. 2016). Males can mate with more than 1 female (polygyny), but females can also mate with several males (polyandry) in the same mating season (Pardo et al. 2016). Like all cancroid crabs, mating occurs only after the molt of females (soft-shelled) (Hartnoll 1969) and mating receptivity of females is relatively short ( 2 to $3 \mathrm{~d}$ ). Males exhibit several strategies to avoid sperm competition, like ejaculate stratification and the placement of a sperm plug (Pardo et al. 2013). Due to the morphology of the seminal receptacle (ventral type, Pardo et al. 2013), last-male sperm precedence is promoted (Diesel 1991), and male-male competition could be intense in this period. Thus, the amount of ejaculate delivered should be context-dependent to increase the probability of paternity (monopaternity in this species, Rojas-Hernández et al. 2014, Pardo et al. 2016).

This study tests if males of M. edwardsii are able to regulate their ejaculate expenditure in (1) response to female traits like female size (proxy of potential fecundity of females), load of ejaculates previously stored in females (proxy of sperm competition), or whether ejaculate transferred is a function of male size relative to seminal material reserves in the vasa deferentia; (2) a socio-sexual context in which a male-biased sex ratio would prompt an increase in the ejaculate load and sperm number delivered to females; and (3) a socio-sexual context in which a female-biased sex ratio would prompt a decrease in ejaculate and sperm delivered.

\section{MATERIALS AND METHODS}

\section{Field survey}

Individuals of Metacarcinus edwardsii were collected from Los Molinos Bay (39 51' S, $73^{\circ} 23^{\prime} \mathrm{W}$ ) on the southern Chilean coast during the mating season (September to January) from 2014 to 2016. Baited traps were deployed at a depth of $15 \mathrm{~m}$ for $24 \mathrm{~h}$. One hundred males and 100 females were selected and transported to the Calfuco Marine Laboratory for experimental matings. In the laboratory, crabs were maintained in $500 \mathrm{l}$ tanks separated by sex, with flowing sea water directly from the Pacific Ocean, air supply and ad libitum food (principally mussels and clams). Mortality and molts were checked every day.

To establish the size relationship between pairing crabs, SCUBA divers searched for pairing crabs in guarding behavior on $30 \mathrm{~m}$ transects $\left(\mathrm{n}=3 \mathrm{mo}^{-1}\right)$ in the rocky subtidal zone of Los Molinos Bay at a depth 
between 5 and $15 \mathrm{~m}$ from October 2015 to April 2016. Females and males were measured (carapace width, CW) in situ and released. Female sizes were plotted against male sizes for visual inspection of the relationship between variables.

\section{Experimental mating}

Two weeks before the start of each mating experiment, the right gonopods of 50 males were ablated (unilateral ablation). Ablation was necessary because M. edwardsii shows trans-molt sperm retention (Pardo et al. 2013) and it was highly probable that some old ejaculate may have remained in female's receptacle before experimental mating. Therefore, the ejaculate and sperm delivered by the experimental male (weight of ejaculate and number of sperm) can be obtained by subtraction between the right (refreshed) and left (not refreshed) receptacle of the same female. Similar methodology has been used in other studies to estimate the ejaculate delivered in 1 mating (Jivoff 2003, Pardo et al. 2013, 2015). The ablation was performed with a clean cut at the base of appendages with surgical scissors. Bilaterally ablated males were used as sentinels to detect receptive females (just before molt) in the female tank. Receptive females were detected by checking daily for the guarding behavior of males. No mortality was detected in the ablated individuals.

Once receptive females were detected, they were paired with unilaterally ablated males in individual 1001 tanks, and copulations were surveyed by means of video recordings. CWs of mating crabs were measured. Three sex-ratio scenarios were performed: (1) equal, 1 female:1 male; (2) male-biased, 1 female: 2 males; and (3) female-biased, 2 females:1 male. Under the equal sex ratio, a large number of pairs $(n=51)$ across a large size range of males and females were examined to explore the individual traits that determine sperm allocation. In the male-biased scenario, 18 pairs were examined and all males used were of similar size $(<5 \%$ difference in $\mathrm{CW}$ between males). Finally, due to the difficulty of obtaining 2 receptive females at the same time, the number of pairs in the female-biased scenario was reduced to 7 cases.

We assumed that (1) males transferred sperm equally through each gonopod, and (2) unilateral gonopod ablation did not affect sperm delivery. First, we correlated the ejaculate weight transferred by unablated males during matings to the left and right receptacles of 37 females (L. M. Pardo unpubl. data). The sperm correlation coefficient was $\mathrm{R}^{2}=$
0.95, showing high symmetry in sperm delivery. Second, we performed an ANCOVA to detect differences in the ejaculate weight (left receptacle) of females mated with unilaterally ablated $(n=51)$ and unablated $(n=37)$ males. Male size was used as a covariate. Both the main effect (experimental ablation) and the interaction with the covariate were not significant (experimental ablation: $F_{1,84}=0.103, \mathrm{p}=$ 0.748 ; experimental ablation $\times$ male size: $F_{1,84}=$ $0.347, \mathrm{p}=0.557$ ), indicating an undetectable effect of unilateral ablation.

\section{Ejaculate/sperm delivery estimation}

After the experimental mating and post-copulatory guarding period (around $2 \mathrm{~d}$ ), both seminal receptacles were extracted from the female. The receptacle wall was slit with forceps, and the contents were placed in a pre-weighed Eppendorf tube $(1.7 \mathrm{ml})$ with $0.5 \mathrm{ml}$ of artificial seawater (Premium Sera ${ }^{\circledR}$ Marin Reef Salt; 30 psu). The Eppendorf tube was weighed again, and the weight of the ejaculate was obtained by subtraction.

To estimate the number of sperm in each ejaculate, $0.1 \mathrm{ml}$ of formalin (5\%) was added to the Eppendorf tube and the contents were homogenized with a Dounce homogenizer for at least 2 min prior to sperm count. Sperm counts were performed in 5 haphazardly selected grids of a Petroff-Hausser counting chamber (volume: $0.02 \mathrm{~mm}^{3}$ ) under a light microscope at $20 \times$ magnification. Three replicates of each seminal receptacle homogenate were taken, and the resulting 15 sperm counts were averaged.

\section{Statistical analysis}

For the equal sex-ratio scenario ( $\mathrm{n}=51$ pairs), a linear model was performed. According to visual inspection of the residuals, the most suitable model for ejaculate and sperm number transferred to females was a Gaussian distribution with a power link function. Akaike's information criterion (AIC) (Burnham \& Anderson 2002) was used to select the individual traits that explained the variation in sperm allocation. The traits tested were size of female, size of male, mean size of female and male, difference in size between female and male (\%), old ejaculate stored and old sperm number in the seminal receptacle of the female. Once these traits were obtained, the linear model was run to test the significant variables in the model. 


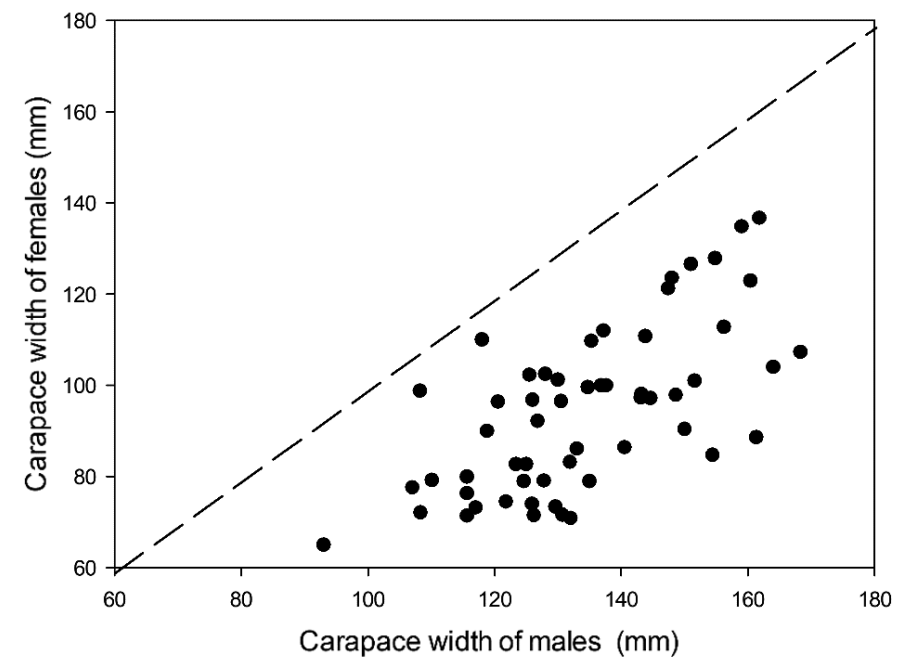

Fig. 1. Size relationship between male and female Metacarcinus edwardsii found in pre-copulatory guarding in the field. Dashed line indicates equal size between sexes

To compare the effect of sex ratio on ejaculate and sperm allocation, a linear model with permutation was performed with sex ratio as a fixed factor and male size as a covariate. This analysis has the advantage of being distribution-free and is suitable for comparing treatments with large differences in replication (more details in https://rdrr.io/cran/lmPerm/ f/inst/doc/lmPerm.pdf). Aovp and lmp from the lmPerm package in $\mathrm{R}$ v.3.3.3 were used to perform the linear model and contrasts to test the effects between treatments and control (equal sex ratio).

\section{RESULTS}

\section{Field mating crab survey}

In total, 59 pairing crabs were found, 51 pairs between October 2015 and February 2016 and 8 in April 2016. Mean male and female size (CW) was $135 \mathrm{~mm}$ $(\max =168.3, \min =93)$ and $94.9 \mathrm{~mm}(\max =136.7$, min $=65)$, respectively. The relationship between female-male size of crabs in pre-copulatory guarding (45 cases, the other 14 pairs were in post-copulatory guarding) showed that males were always larger than females in the field. The size difference between males and females was around $31 \pm 10 \%$ (mean \pm SD) (Fig. 1).

\section{Ejaculate/sperm stored in experimental females}

Left seminal receptacles that were not refreshed during the experimental mating (i.e. control recepta- cles to determine previously stored loads of ejaculate in females) always had measurable amounts of sperm stored, except for 2 individuals which had empty receptacles (possibly virgin females). Both ejaculate and sperm number stored in receptacles showed significant exponential relationships with the size of females (Fig. 2).

\section{Ejaculate/sperm allocation under equal sex ratio}

Under an equal sex ratio, the model (selected by AIC) which best explained the variation in the weight of ejaculate delivered by males only included male size. Variables such as female size, size difference between females and males (\%), or old ejaculate stored were not selected by the model. The linear model indicated that male size significantly influenced the quantity of ejaculate delivered (Wald test $=11.8, \mathrm{df}=1$,
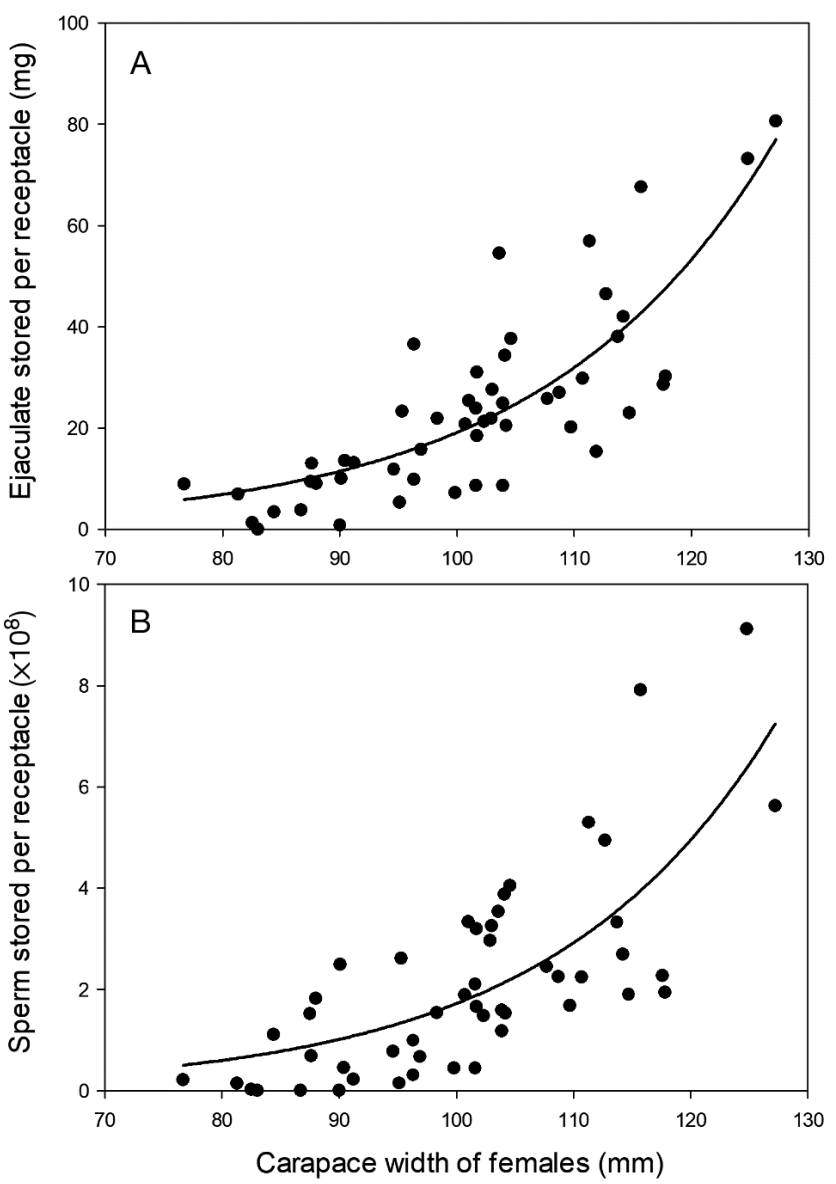

Fig. 2. (A) Ejaculate stored in seminal receptacles of female Metacarcinus edwardsii in relation to their size (carapace width, CW). Ejaculate stored $=0.12 \times \mathrm{e}^{(0.05 \times \mathrm{CW})}, \mathrm{R}^{2}=0.7$. (B) Mean sperm number stored in seminal receptacle in relation to female size. Sperm stored $=867264 \times \mathrm{e}^{(0.05 \times \mathrm{CW})}$, $\mathrm{R}^{2}=0.6$. Significant regressions, $\mathrm{p}<0.05$ 
$\mathrm{p}<0.001$ ) (Fig. 3A). The best model for the number of sperm delivered by males included male size and size difference between females and males (\%). However, only male size was significant (male size: Wald test $=$ 18.9, $\mathrm{df}=1, \mathrm{p}<0.001$; size difference: Wald test $=2.7$, $\mathrm{df}=1, \mathrm{p}=0.09$ ) (Fig. 3B). The relationship between the weight of ejaculate delivered (principally composed of seminal material) and the number of sperm showed a saturated phase when large ejaculate weight values were reached. This indicates that large males transfer proportionally more seminal fluid than sperm compared to small males (Fig. 4).

\section{Ejaculate/sperm allocation under biased sex ratios}

Under a male-biased scenario, males allocated more ejaculate to females in comparison to males
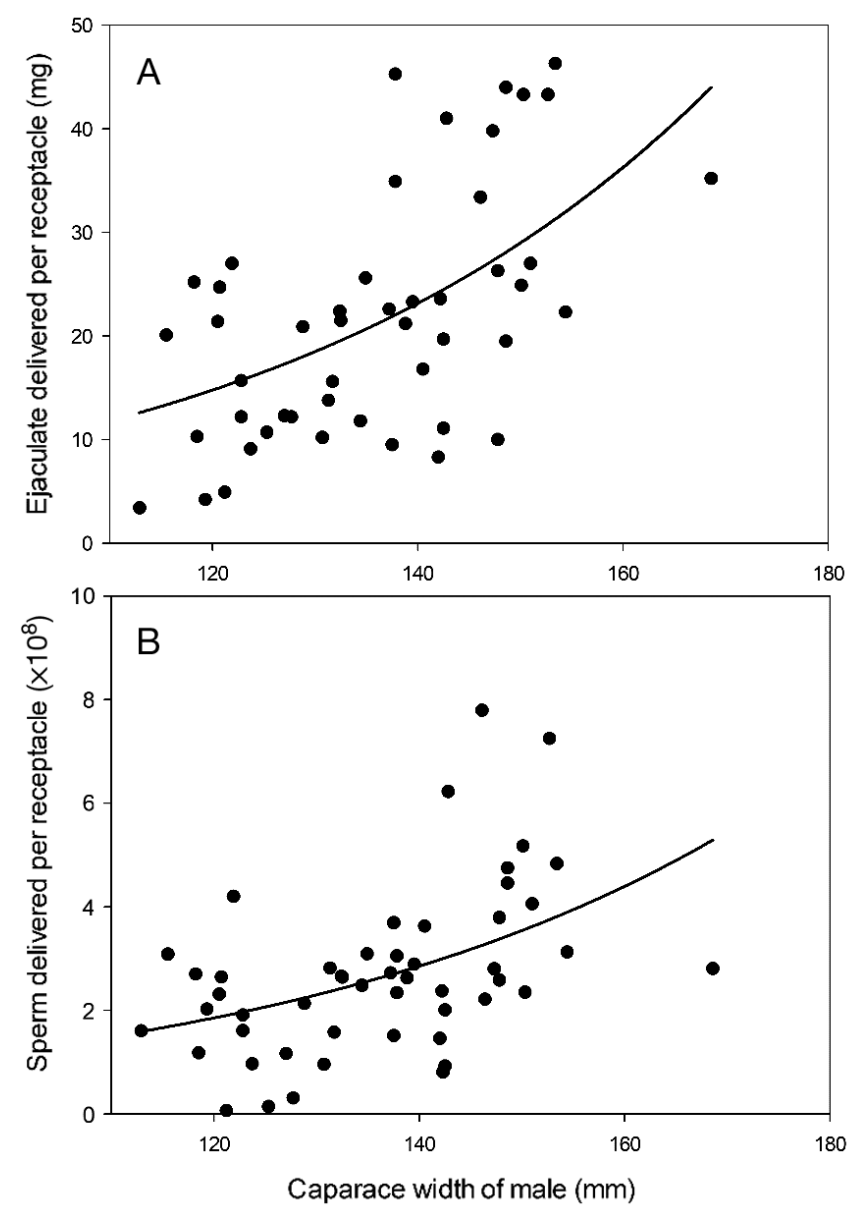

Fig. 3. (A) Ejaculate delivered to seminal receptacles of Metacarcinus edwardsii in relation to male size (carapace width, CW). Ejaculate delivered $=\mathrm{e}^{(0.02 \times C W)}, \mathrm{R}^{2}=0.3$. (B) Mean sperm number stored in seminal receptacles in relation to male size. Sperm delivered $=13952974 \times \mathrm{e}^{(0.02 \times \mathrm{CW})}$, $\mathrm{R}^{2}=0.2$. Significant regressions, $\mathrm{p}<0.05$

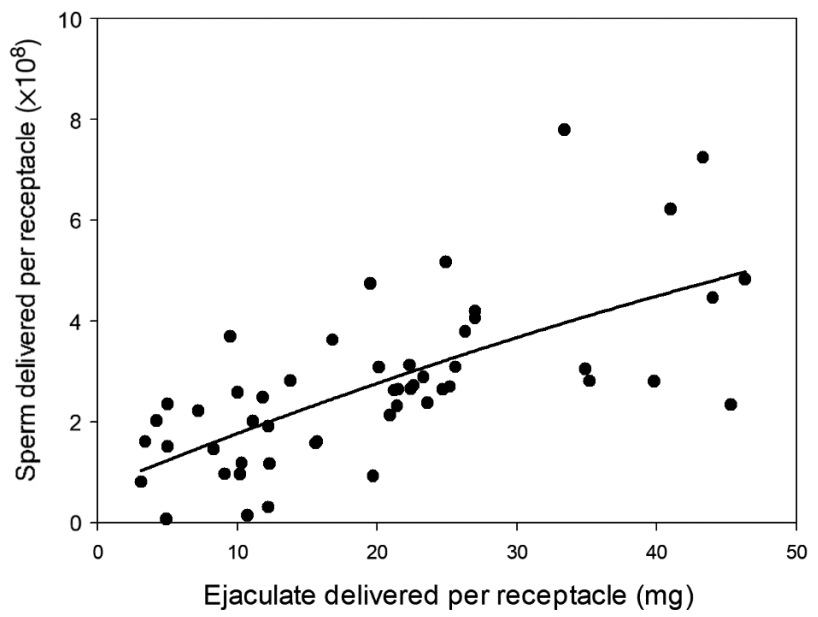

Fig. 4. Relationship between weight of the ejaculate delivered by male Metacarcinus edwardsii and number of sperm in the ejaculate in 1 receptacle. Data correspond to experimental mating under the equal sex ratio. ED $=68887034+$ $11248176 \times \mathrm{SD}-43044 \times \mathrm{SD}^{2}, \mathrm{R}^{2}=0.5$. ED: ejaculate delivered; SD: sperm delivered. Significant regressions, $\mathrm{p}<0.05$

under an equal sex ratio and a female-biased scenario (Table 1, Fig. 5). In contrast, males under a female-biased versus equal sex ratio scenario (i.e. control) did not show any differences in ejaculate allocation (Fig. 5B). On the other hand, sperm allocation was not different between treatments and control (Table 1, Fig. 6A,B). In both cases, male size was included in the model as a covariate.

Table 1. Permutation test of the linear model comparing the effects of male size (covariate) and sex ratio (fixed factor) on ejaculate and sperm delivered by males to the seminal receptacles of females

\begin{tabular}{|lcccc|}
\hline Factor & df & MS & $\begin{array}{c}\text { No. of } \\
\text { iterations }\end{array}$ & $p$ \\
\hline Ejaculate delivered & & & & \\
$\quad$ Male size & 1 & 1639.7 & 5000 & 0.001 \\
$\quad$ Sex ratio & 2 & 267.7 & 1696 & 0.056 \\
Residual & 71 & 110.1 & & \\
Contrast test & & & & \\
Equal-Male-biased & & 3217 & 0.031 & \\
Equal-Female-biased & & 51 & 0.902 & \\
Sperm delivered & & & & \\
$\quad$ Male size & 1 & $4.16 \times 10^{17}$ & 5000 & $<0.001$ \\
$\quad$ Sex ratio & 2 & $9.85 \times 10^{15}$ & 112 & 0.759 \\
Residual & 69 & $1.83 \times 10^{16}$ & & \\
Contrast test & & & & \\
Equal-Male-biased & & 205 & 0.332 & \\
Equal-Female-biased & & 51 & 0.961 & \\
\hline
\end{tabular}




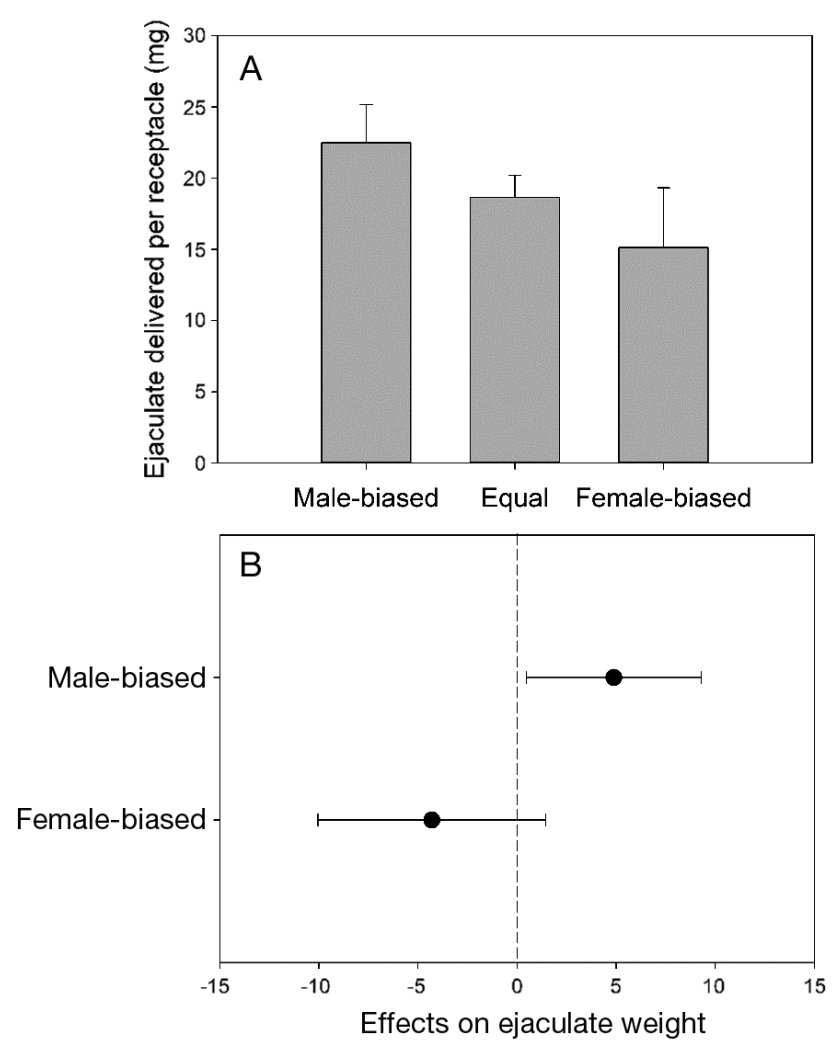

Fig. 5. (A) Adjusted means of the weight of ejaculate delivered by male Metacarcinus edwardsii under different sexratio scenarios. (B) Mean effect of the treatments (biased sex ratios) in contrast with the control (equal sex ratio) and their confidence limits $( \pm 95 \%)$

\section{DISCUSSION}

In a balanced sex-ratio scenario, male Metacarcinus edwardsii did not show plasticity in the allocation of their ejaculate stock. Female traits did not influence the ejaculate or sperm number transferred. Both the amount of ejaculate and number of sperm delivered by males had a positive relationship with male size. Larger males (>140 mm CW) have a greater storage capacity of seminal material than smaller ones and scale the ejaculate transfer exponentially, as would be expected between a linear variable $(\mathrm{CW})$ and a volume (ejaculate). Thus, larger males were able to pass more seminal material to females, but they did not adjust their ejaculate/sperm delivery to female size (a proxy of reproductive potential, Pardo et al. 2016) or fullness of the seminal receptacle of the females (proxy of risk of sperm competition from old sperm stored).

Given that the costs of seminal liquid are high (Dewsbury 1982), the disproportion between the ejaculate and the number of sperm delivered relative to male size indicates that larger males invest more in

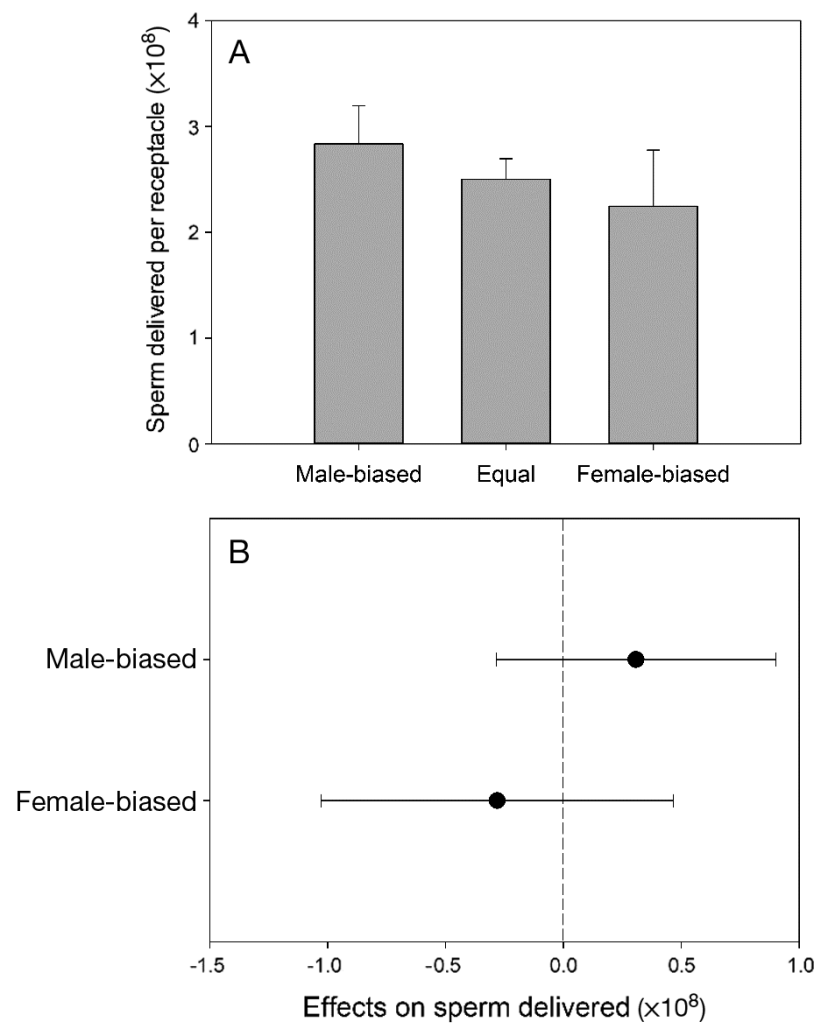

Fig. 6. (A) Adjusted means of number of sperm delivered by male Metacarcinus edwardsii under different sex-ratio scenarios. (B) Mean effect of the treatments (biased sex ratios) in contrast with the control (equal sex ratio) and their confidence limits $( \pm 95 \%)$

reproduction. So why could it be more important to deliver a greater amount of seminal fluid than a higher number of sperm? The explanation could be associated with the multiple functions of the seminal fluids beyond their nutritional or antimicrobial contributions to increase the survival of gametes (Subramoniam 1993). Seminal receptacles are extensible organs, where individual ejaculates are stored in discrete packages that are progressively displaced towards the blind end, forming an ejaculate stratification pattern (Sainte-Marie et al. 2000, Jensen \& Bentzen 2012, Pardo et al. 2013, Antunes et al. 2016, Farias et al. 2017). The ejaculates are separated by seminal fluid layers (also called seminal gel) deposited by the last male to avoid sperm mixing and to improve the probability of fertilization. Ejaculate stratification is a useful strategy to ensure paternity especially in species in which the oviduct connects ventrally to the seminal receptacle close to the entrance of the vagina (ventral type). Sperm of crustaceans are not motile, and fertilization occurs when oocytes pass through the seminal receptacle to the entrance of the vagina. Thus, sperm deposited by the 
last male are placed closer to the vagina and have a higher probability of fertilization.

Seminal fluids also seem to be implied in the formation of the sperm plug (internal and external) (Diesel 1991), which is another strategy of males to avoid multiple paternity. Therefore, larger males might deposit more seminal gel than smaller ones and a well-structured sperm plug might be formed. Thus, an increase in the amount of seminal fluids transferred to females rather than sperm could be a competitive advantage for larger males in a sperm competition context.

A similar pattern has been found in the crab species Callinectes sapidus (Kendall et al. 2001). The disproportion between the delivery of seminal fluid and sperm number could be associated with high activity of an accessory gland (also called caeca), where seminal gel apparently is produced (Sainte-Marie \& Sainte-Marie 1999). The reproductive tract of $M$. edwardsii has been described only partially (Pardo et al. 2009), though it corresponds to a simple tract without lateral outpocketing or an accessory gland, as in portunids and majoids (Sainte-Marie \& Sainte-Marie 1999, Zara et al. 2012). Thus, the thickened middle section of the vasa deferentia of $M$. edwardsii, which exhibits a glandular epithelium (Pardo et al. 2009), should be responsible for the high levels of seminal fluids close to the mating season in this species.

Wedell et al. (2002) showed that males across a large range of taxa can be sensitive to the risk of sperm competition, increasing their ejaculate size according to the presence of rival males. As expected under male-biased sex ratio scenarios, the ejaculates delivered by male crabs were heavier than those under equal sex ratios. This indicates that males were able to perceive the socio-sexual context and change their ejaculate expenditure accordingly. In M. edwardsii, this was expected because in previous experiments (Pardo et al. 2016), copulation time lasted longer under male-biased sex ratio scenarios. This indicates an increase in the seminal materials transferred to females, as has been demonstrated in other crabs (Rodgers et al. 2011). Increase in the ejaculate amount delivered by males under the risk of sperm competition has been described a few times in brachyuran crabs such as C. sapidus and Chionoecetes opilio (Jivoff 1997, Rondeau \& Sainte-Marie 2001) but seems to be more common in other decapods like lobsters and Anomura (Sainte-Marie 2007. Sato \& Goshima 2007).

Plasticity in ejaculate allocation was not detected when 1 male of $M$. edwardsii was exposed to 2 receptive females. Consistently, Pardo et al. (2016) also did not find differences in the duration of copulation between equal and female-biased sex ratios. These results were not expected because males should decrease the ejaculate/sperm allocation under femalebiased sex ratios to maximize future mating opportunities (Parker et al. 1997, von Son \& Thiel 2006). However, in species which are able to store viable sperm for years in their seminal receptacles (as in M. edwardsii, Pardo et al. 2017), a reduction of the amount of ejaculate delivered could implicate a high risk of sperm competition because males seem to be unable to evaluate the amount of the ejaculate stored in females before mating.

Notably, in this study, the sex ratio scenario biased to females was the minimum possible (2 females: 1 male), which could not have been enough to trigger a prudent behavior in the allocation of ejaculate in this species. In addition, the lower replication $(n=7)$ in comparison to other treatments could be insufficient to detect differences if they existed (i.e. statistical power). Therefore, the conclusion that this species does not exhibit sperm allocation under a female-biased sex ratio should be taken with caution.

Furthermore, under a female-biased sex ratio, males of the snow crab C. opilio allocate less ejaculate (Rondeau \& Sainte-Marie 2001), like other decapods such as crayfish (Rubolini et al. 2006) or king crabs (Sato \& Goshima 2007). This indicates that the prudent use of ejaculate reserves seems to be generalized in decapods.

The behavior of females and their role in prolonging copulation or stimulating males to transfer larger ejaculates have not been included as potential variables here but have been suggested in some insects (Kelly \& Gwynne 2017). The female role during mating is frequently assumed to be reactive, with respect to the active male, but this could be only a stereotyped vision (Perry \& Rowe 2012). However, in $M$. edwardsii, this assumption should be correct given that females mate in a very vulnerable stage, just after their molt (soft shelled), in contrast to males that are in the intermolt stage (hard shelled).

In conclusion, $M$. edwardsii presents a low level of ejaculate allocation, responding only when competitive males are perceived. This is in agreement with the seminal economy hypothesis because the risk of sperm competition is high from multiple mates. Further, multiple paternity has not been detected in $M$. edwardsii (Pardo et al. 2016), and last-male sperm precedence should be the rule for fertilization in species with the ventral-type seminal receptacle (McLay \& López-Greco 2011) such as M. edwardsii (Pardo et al. 2013). Therefore, males increase ejaculate de- 
livery under the risk of sperm competition. The evidence indicates that a greater amount of ejaculate transferred to females does not necessarily involve more sperm. More seminal fluids can be of advantage because they can be used in several strategies to avoid sperm competition, like the stratification of precedent sperm packages and the formation of sperm plugs.

In harvested crabs, like $M$. edwardsii, the low capacity of males to allocate their ejaculates prudently depending on future mating opportunities could explain why this species undergoes ejaculate depletion under a female-biased sex ratio triggered by intense fishery (Pardo et al. 2015). Ejaculate depletion in males promotes sperm limitation in females, which has also been detected in this species in populations with high exploitation rates (Pardo et al. 2017). Reduction of male size in a population can also contribute to sperm limitation (Pardo et al. 2017), because larger males transfer disproportionally more ejaculate to females than smaller ones and they are exclusively able to embrace large females during their receptive period (Fig. 1). Thus, depending on the mating strategy, certain crab species may be especially responsive to male-biased management strategies.

Acknowledgements. L.M.P. is grateful for the financial support of the FONDECYT 1150388 and FONDAP IDEAL 15150003. The authors thank Juan Pablo Fuentes for his help in the laboratory experiments. The authors also thank the 3 anonymous reviewers whose useful comments and suggestions improved the manuscript. All experimental work was conducted in Chile and complied with existing laws and regulations.

\section{LITERATURE CITED}

Andersson M (1994) Sexual selection. Princeton University Press, Princeton, NJ

Antunes M, Zara FJ, López-Greco LS, Negreiros-Fransozo ML (2016) Morphological analysis of the female reproductive system of Stenorhynchus seticornis (Brachyura: Inachoididae) and comparisons with other Majoidea. Invertebr Biol 135:75-86

Burnham KP, Anderson DR (2002) Model selection and multimodel inference: a practical information-theoretic approach. Springer, New York, NY

Dewsbury DA (1982) Ejaculate cost and male choice. Am Nat 119:601-610

Diesel R (1991) Sperm competition and the evolution of mating behavior in Brachyura, with special reference to spider crabs (Decapoda: Majidae). In: Bauer RT, Martin JW (eds) Crustacean sexual biology. Columbia University Press, New York, NY, p 145-163

Farias NE, Spivak ED, Luppi T (2017) Functional morphology of the female reproductive system of a crab with highly extensible seminal receptacles and extreme sperm storage capacity. J Morphol 278:919-935

Fischer S, Thatje S (2016) Temperature effects on life-history traits cause challenges to the management of brachyuran crab fisheries in the Humboldt Current: a review. Fish Res 183:461-468

Hartnoll RG (1969) Mating in the Brachyura. Crustaceana 16:161-181

Jensen PC, Bentzen P (2012) A molecular dissection of the mating system of the Dungeness crab, Metacarcinus magister (Brachyura: Cancridae). J Crustac Biol 32:443-456

Jivoff P (1997) The relative roles of predation and sperm competition on the duration of the post-copulatory association between the sexes in the blue crab, Callinectes sapidus. Behav Ecol Sociobiol 40:175-185

Jivoff P (2003) A review of male mating success in the blue crab, Callinectes sapidus, in reference to the potential for fisheries-induced sperm limitation. Bull Mar Sci 72: 273-286

Kelly CD, Gwynne DT (2017) Do male Cook Strait giant weta prudently allocate sperm? J Insect Behav 30:308-317

*Kendall MS, Wolcott DL, Wolcott TG, Hines AH (2001) Reproductive potential of individual male blue crabs, Callinectes sapidus, in a fished population: depletion and recovery of sperm number and seminal fluid. Can J Fish Aquat Sci 58:1168-1177

MacDiarmid AB, Butler MJ (1999) Sperm economy and sperm limitation in spiny lobsters. Behav Ecol Sociobiol 46:14-24

McLay CL, López-Greco LS (2011) A hypothesis about the origin of sperm storage in the Eubrachyura, the effects of seminal receptacle structure on mating strategies and the evolution of crab diversity: How did a race to be first become a race to be last? Zool Anz 250:378-406

* Pardo LM, Fuentes JP, Olguin A, Orensanz JM (2009) Reproductive maturity in the edible Chilean crab Cancer edwardsii: methodological and management considerations. J Mar Biol Assoc UK 89:1627-1634

* Pardo LM, Riveros M, Fuentes JP, López-Greco L (2013) Functional morphology of the seminal receptacle in the crab Metacarcinus edwardsii. Invertebr Biol 132:386-393

* Pardo LM, Rosas Y, Fuentes JF, Riveros MP, Chaparro OR (2015) Fishery induces sperm depletion and reduction in male reproductive potential for crab species under malebiased harvest strategy. PLOS ONE 10:e0115525

*Pardo LM, Riveros MP, Fuentes JP, Rojas-Hernández N, Véliz D (2016) An effective sperm competition avoidance strategy in crabs drives genetic monogamy despite evidence of polyandry. Behav Ecol Sociobiol 70:73-81

Pardo LM, Riveros MP, Fuentes JP, Pinochet R, Cárdenas C, Sainte-Marie B (2017) High fishing intensity reduces females' sperm reserve and brood fecundity in a eubrachyuran crab subject to sex- and size-biased harvest. ICES J Mar Sci 74:2459-2469

*Parker GA, Pizzari T (2010) Sperm competition and ejaculate economics. Biol Rev Camb Philos Soc 85:897-934

*Parker GA, Ball MA, Stockley P, Gage MJ (1997) Sperm competition games: a prospective analysis of risk assessment. Proc R Soc B 264:1793-1802

* Perry JC, Rowe L (2012) Sex role stereotyping and sexual conflict theory. Anim Behav 83:e10-e13

* Perry JC, Sirot L, Wigby S (2013) The seminal symphony: how to compose an ejaculate. Trends Ecol Evol 28: 414-422

Pitnick S, Markow TA (1994) Male gametic strategies: sperm size, testes size, and the allocation of ejaculate among 
successive mates by the sperm-limited fly Drosophila pachea and its relatives. Am Nat 143:785-819

Reinhold K, Kurtz L, Engqvist L (2002) Cryptic male choice: sperm allocation strategies when female quality varies. J Evol Biol 15:201-209

Rodgers PJ, Reaka ML, Hines AH (2011) A comparative analysis of sperm storage and mating strategies in five species of brachyuran crabs. Mar Biol 158:1733-1742

Rojas-Hernández N, Veliz D, Pardo LM (2014) Use of novel microsatellite markers for population and paternity analysis in the commercially important crab Metacarcinus edwardsii (Brachyura: Cancridae). Mar Biol Res 10: 839-844

Rondeau A, Sainte-Marie B (2001) Variable mate-guarding time and sperm allocation by male snow crabs (Chionoecetes opilio) in response to sexual competition, and their impact on the mating success of females. Biol Bull 201: 204-217

Rubolini D, Galeotti P, Ferrari G, Spairani M, Bernini F, Fasola M (2006) Sperm allocation in relation to male traits, female size, and copulation behaviour in freshwater crayfish species. Behav Ecol Sociobiol 60:212-219

Sainte-Marie B (2007) Sperm demand and allocation in decapod crustaceans. In: Duffy JE, Thiel M (eds) Evolutionary ecology of social and sexual systems: crustaceans as model organisms. Oxford University Press, New York, NY, p 191-210

Sainte-Marie B, Lovrich GA (1994) Delivery and storage of sperm at first mating of female Chionoecetes opilio (Brachyura: Majidae) in relation to size and morphometric maturity of male parent. J Crustac Biol 14:508-521

Sainte-Marie G, Sainte-Marie B (1999) Reproductive products in the adult snow crab (Chionoecetes opilio). I. Observations on spermiogenesis and spermatophore formation in the vas deferens. Can J Zool 77:440-450

Sainte-Marie G, Sainte-Marie B, Sévigny JM (2000) Ejacu-

Editorial responsibility: Roderick Finn,

Bergen, Norway late-storage patterns and the site of fertilization in female snow crabs (Chionoecetes opilio; Brachyura, Majidae). Can J Zool 78:1902-1917

Sal Moyano MP, Gavio MA, Luppi T (2015) Different sperm allocation strategies in two populations of the semiterrestrial crab Neohelice granulata (Brachyura, Grapsoidea, Varunidae). Mar Ecol 37:1-15

Sato T, Goshima S (2007) Effects of risk of sperm competition, female size, and male size on number of ejaculated sperm in the stone crab Hapalogaster dentata. J Crustac Biol 27:570-575

* Sato T, Ashidate M, Jinbo T, Goshima S (2006) Variation of sperm allocation with male size and recovery rate of sperm numbers in spiny king crab Paralithodes brevipes. Mar Ecol Prog Ser 312:189-199

Subramoniam T (1993) Spermatophores and sperm transfer in marine crustaceans. In: Blaxter JHS, Southward AJ (eds) Advances in marine biology, Vol 29. Academic Press, New York, NY, p 129-214

*Vinuesa J, Lovrich GA, Tapella (1999) New localities for Crustacea Decapoda in the Magallean region, southern South America. Sci Mar (Supl1):321-323

von Son TC, Thiel M (2006) Mating behaviour of male rock shrimp, Rhynchocinetes typus (Decapoda: Caridea): effect of recent mating history and predation risk. J Exp Mar Biol Ecol 71:61-70

* Wedell N, Gage MJG, Parker GA (2002) Sperm competition, male prudence and sperm-limited females. Trends Ecol Evol 17:313-320

*Wigby S, Sirot LK, Linklater JR, Buehner N and others (2009) Seminal fluid protein allocation and male reproductive success. Curr Biol 19:751-757

Zara FJ, Toyama MH, Caetano FH, López-Greco LS (2012) Spermatogenesis, spermatophore, and seminal fluid production in the adult blue crab Callinectes danae (Portunidae). J Crustac Biol 32:249-262

Submitted: December 13, 2017; Accepted: March 9, 2018 Proofs received from author(s): April 23, 2018 